\title{
Residual Stress Distributions in Cold-Sprayed Copper 3D-Printed Parts
}

\author{
Rebecca Sinclair-Adamson ${ }^{1}$ - Vladimir Luzin ${ }^{2,3} \cdot$ Andrew Duguid $^{4} \cdot$ \\ Krishnan Kannoorpatti ${ }^{1} \cdot$ Rebecca Murray $^{1}$
}

Submitted: 14 November 2019/in revised form: 16 March 2020/Published online: 25 May 2020

(C) The Author(s) 2020

\begin{abstract}
Cold-spray additive manufacturing (CSAM) builds strong, dense metal parts from powder feedstock without melting and offers potential advantages over alternatives such as casting, liquid phase sintering, laser or e-beam melting or welding. Considerable effort is required to relieve residual stresses that arise from melt/freeze cycling in these methods. While CSAM does not involve melting, it imposes high strain rates on the feedstock and stress anisotropies due to complex build paths. This project explores residual stress in two CSAM objects. The CSAM components were produced from $99 \%$ pure copper powder $(\mathrm{D} 50=17 \mu \mathrm{m})$ : (1) a cylinder $(\varnothing=15 \mathrm{~mm}$, height $=$ $100 \mathrm{~mm}$, weight $=145 \mathrm{~g}$ ) and (2) a funnel (upper outer $\varnothing=60 \mathrm{~mm}$, lower outer $\varnothing=40 \mathrm{~mm}$, wall thickness $=8 \mathrm{~mm}$, weight $=547 \mathrm{~g}$ ). The non-heat-treated components were strain-scanned using a residual stress neutron diffractometer. Maximum residual stresses in any
\end{abstract}

This article is part of a special topical focus in the Journal of Thermal Spray Technology on Advanced Residual Stress Analysis in Thermal Spray and Cold Spray Processes. This issue was organised by Dr.

Vladimir Luzin, Australian Centre for Neutron Scattering; Dr. Seiji Kuroda, National Institute of Materials Science; Dr. Shuo Yin, Trinity College Dublin; and Dr. Andrew Ang, Swinburne University of Technology.

Rebecca Murray

rebecca.murray@cdu.edu.au

1 Advanced Manufacturing Alliance, Charles Darwin University, Ellengowan Drive, Casuarina, NT 0810, Australia

2 Australian Nuclear Science and Technology Organization, Lucas Heights, NSW 2234, Australia

3 School of Engineering, The University of Newcastle, Callaghan, NSW 2308, Australia

4 SPEE3D, Dandenong, VIC 3175, Australia direction were: tensile: $103 \pm 16 \mathrm{MPa}$ (cylinder) and $100 \pm 23 \mathrm{MPa}$ (funnel); compression: $58 \pm 16 \mathrm{MPa}$ (cylinder) and $123 \pm 23 \mathrm{MPa}$ (funnel). Compared to the literature, the tensile residual stresses measured in the CSAM components were lower than those measured in cast materials, laser or welding AM methods, and numerical modelling of cold-spray coatings, while within the wide range reported for measurements in cold-spray coatings. These comparatively low residual stresses suggest CSAM is a promising manufacturing method where high residual stresses are undesirable.

Keywords additive manufacturing - casting - cold spray · cold-spray additive manufacturing - copper - neutron · residual stress

\section{Introduction}

The principle of cold-spray (CS) manufacturing was established in the Soviet Union in the 1980s (Ref 1). When powder is sprayed towards a substrate, it can produce coatings. Powders suitable for cold spray include metals, some ceramics, and some polymers. In cold spray, powder is suspended in a hot, pressurised carrier gas. The carrier gas is heated not to melt the powder, but rather to accelerate the powder from a de Laval nozzle towards a substrate with high kinetic energy. Adhesion of the metal powder occurs due to the deformation of the particles. More recently, advancement in CS technology is moving towards production of freeform and near-net-shape components, arguably creating a separate branch of AM called cold gas dynamic manufacturing (Ref 2) or cold-spray additive manufacturing (CSAM) (Ref 3). Presently, there are several commercial CSAM systems on the market 
including modular units made by SPEE3D $(\operatorname{Ref} 4,5)$ and Titomic (Ref 6-8). SPEE3D machines are geared towards freeform components, whereas Titomic machines typically produce axisymmetric components. Custom-built set-ups are also possible where freeform components are required, assembled from commercially available cold-spray systems and commercially available robotic controls, for example an Impact Innovations (Haun, Germany) 5/11 cold-spray gun guided by an ABB (Zurich, Switzerland) $46006-\mathrm{DoF}$ robot (Ref 9), including systems with robotic movement for both the cold-spray nozzle and the substrate (Ref 10).

As for any other AM technique, the issue of formation of residual stress and its mitigation is important, since undesirable residual stress can create distortions in AM components and/or cracking. High-magnitude residual stresses have been reported for traditional additively manufacturing techniques like direct metal deposition (DMD), selective laser melting (SLM), wire arc additive manufacturing (WAAM), etc. A steel component produced by DMD has been reported with residual stresses varying between 300 and $-300 \mathrm{MPa}$, as measured by neutron strain scanning (Ref 11). A component made using WAAM had stresses in the range 450 to $-200 \mathrm{MPa}$ in the longitudinal direction (Ref 12). Residual stresses have been reported in cast copper in the ranges of $150-200 \mathrm{MPa}$ (hoop) and 50-125 MPa (axial) before welding (Ref 13). With different micro-mechanical principles, CSAM is thought to create different residual stresses from other novel and traditional manufacturing techniques.

Residual stress has been measured in cold-spray coatings (Ref 14-25) but not previously reported in bulk coldspray materials. The literature discusses competing effects on the deposition stress (stress associated with the cold spray process only) from peening (Ref 15-18, 21-23), thermal mismatch between substrate and coating (Ref 15-18, 21-23), and quenching (Ref 16, 18, 22, 23). The dominating effect may depend on material combination and many process parameters including spray temperature. In some cases (Ref 15, 17, 21, 24), thermal mismatch and quenching effects are seen as a single effect, and in others, residual stresses arising from thermal mismatch are reported separately from deposition stress (Ref 16, 25).

Peening effects on deposition stress arise because of plastic deformation on impact and, where peening dominates the stress balance, give rise to compressive stress at the coating surface. Several studies (Ref 15-17, 21-24) have compared measured residual stress in cold-spray coatings to a model by Tsui and Clyne for coatings (Ref 26), found compressive surface stresses, and concluded that peening was the dominant effect on deposition stress in those systems.

Thermal mismatch effects on residual stress arise when the substrate and coating have dissimilar coefficients of thermal expansion and, where thermal mismatch dominates, can give rise to tensile surface stress. Some studies (Ref 18, 21,24) have compared measured residual stress in cold-spray coatings to the coatings model by Tsui and Clyne (Ref 26), found tensile surface stresses, and concluded that thermal mismatch was the dominant effect on deposition stress in the reported systems.

Quenching effects on deposition stress arise from contraction of individual splats as they cool, and therefore, where they dominate the stress balance, give rise to tensile surface stress. A few studies (Ref 18, 25) have found quenching dominant stresses in cold-spray coatings, and it appears that these systems involve higher carrier gas temperatures than other cold-spray coatings reported in the literature.

Residual stress in cold-sprayed copper coatings has been reported as compressive deposition stress with magnitudes from -20 to $-100 \mathrm{MPa}(\operatorname{Ref} 14,15)$, depending on powder morphology (Ref 14) and on spraying parameters (Ref 15). Apart from the above-mentioned mechanical (largescale stresses), stress fields are highly inhomogeneous on the scale of splat and localised stresses can reach much higher magnitudes of several hundred MPa depending on angle of deposition (Ref 27) and varying strongly between compressive and tensile within each splat but increasing with increasing spray velocity up to a certain limit (Ref 28).

Residual stresses have also been reported to have comparable, relatively small magnitudes (usually under $-100 \mathrm{MPa}$ ) in cold-sprayed coatings of other metals and alloys (Ref 17, 19-21) showing the overall tendency to produce mostly compressive deposition stress (Ref 29).

Strong variations in small-range stresses between tensile and compressive within individual splats and layers (found using numerical modelling, Ref 27, 28) are posited to arise from the high plastic deformation of metal particles on impact. However, this experiment aims to measure macrostresses and is not expected to be able to quantify microstresses.

Residual strains were measured in the cold-sprayed copper parts by neutron diffraction. The neutron diffraction technique was required to measure strain inside the parts due to their thickness. Compared with synchrotron radiation for strain scanning (Ref 30), the neutron technique can reach greater depths and enables a far better localisation of the gauge volume (cubic vs. long diamond shape). 


\section{Experimental Procedure}

\section{Component Production: 3D Printing}

The specimens were printed from 99\% pure copper powder, supplied by AMPS, Cu-325 mesh. The specimens were made using the LightSPEE3D cold-spray metal printer (SPEE3D, Darwin NT, Australia) using pressurised air at 30 bar and $400{ }^{\circ} \mathrm{C}$ as the carrier gas.

The powder is transported from the powder feeder to the nozzle using gas transport. At the same time, air for propulsion is preheated and fed to the nozzle pre-chamber. The propelling gas increases the velocity of the aerosolised powder. The LightSPEE3D printer is an upstream CS device, meaning that the powder and carrier gas contact one another in a pre-chamber upstream of the nozzle. During the contact between the powder and the preheated propelling gas in the pre-chamber, the powder warms up but does not melt.

The powder feed rate was $20 \mathrm{~g} / \mathrm{min}$. The LightSPEE3D printer has a static de Laval nozzle, $200 \mathrm{~mm}$ long, with a throat diameter of $1 \mathrm{~mm}$ and an inside diameter at the nozzle of $6.4 \mathrm{~mm}$. The substrate is attached to a 6-axis robotic arm. The robot head speed was $100 \mathrm{~mm} / \mathrm{s}$. The deposition strategy was raster with a rotation between layers. Consequently, the regions of each sub-layer are not sprayed in the same order.

As the powder exits the de Laval nozzle, expansion causes a sharp drop in the temperature of the propelling gas and powder. The stand-off distance of the nozzle from the substrate was $16 \mathrm{~mm}$. As the powder impacts the substrate, it deforms, creating a low porosity solid with microstructural gradients between what was the centre of each powder particle towards the joins between the particles.

The printing process takes place layer by layer. Material layers are built up first on an aluminium 6061 substrate $(80 \times 80 \times 3 \mathrm{~mm})$ and then on the previously deposited layers.

The proprietary printer control software breaks down the design into slices (1.68 $\mathrm{mm}$ thick). However, the software treats edging material differently from infill. The edges of each slice cannot be formed with the nozzle perpendicular so the relative angle of the base plate and nozzle is adjusted to provide an acute spray angle $\left(45^{\circ}\right)$. After each layer is completed, the printer deposits the subsequent layer on top of it. The printed specimens are shown in Fig. 1.

\section{Hardness and Microscopy}

After neutron strain scanning, microscopy sections in the $\mathrm{X}-\mathrm{Y}$ and Z-planes as shown in Fig. 5 were cut from the specimens using an ATM Brillant 221 cutting machine.
The pieces were encapsulated using a Struers CitoPress-1, and the cut surfaces polished using a Struers TegraPol-15. First, Vickers' hardness testing (Struers DuraScan) using a force of $0.05 \mathrm{~kg}$ for the indent were performed over grids of points covering areas of $1.6 \mathrm{~mm}$ by $5.4 \mathrm{~mm}$, chosen so that the longer dimension extended from as close to the printed surface as possible to the middle of the specimen. Following hardness testing, the polished surfaces were repolished and etched. Light microscopy was performed using a Nikon MA100 microscope with a $50 \times$ lens magnification.

\section{Compressive Testing}

Two 38-mm long, 13-mm-diameter compression cylinders were cut from the cylinder specimen as indicated in Fig. 1. To these were added three additional cylinders printed from the same batch of copper powder and using the same print settings to perform mechanical testing. The compression tests were performed according to ASTM E9 using a Kudale Tensometer with a nominal strain rate of $0.005 \mathrm{~m} / \mathrm{m} . \mathrm{min}$, a maximum applied compressive load of $7 \mathrm{kN}$ (equating to $53 \pm 1.5 \mathrm{MPa}$ ), and a sampling rate of $60 \mathrm{~ms}$. Strain gauges were used to measure longitudinal and circumferential strains and calculate Young's modulus and Poisson's ratio. The compression testing remained within the elastic limit of the material and the specimens were unloaded and retested two to four times each to give additional data points.

\section{Neutron Strain Scanning: Principles of Strain Measurements and Stress Calculations}

Although the theory and practical applications of the neutron diffraction techniques for stress analysis are well known and well established e.g. (Ref 31, 32), a brief description is also given here for completeness.

When a neutron beam of wavelength $\lambda$ strikes a crystalline material that has an inter-planar spacing $d_{h k l}$ comparable with $\lambda$, a diffraction pattern is generated in which the position of each plane $(h k l)$ is obtained using the Bragg relation:

$2 d_{h k l} \sin \theta_{h k l}=\lambda$

The angle $2 \theta$ of diffraction for each measurement point was plotted and curve fitted to evaluate peak position and intensity, full-width half-maximum and peak fitting errors.

Altered lattice spacings of a particular crystal plane $h \mathrm{kl}$, $d_{h k l}$, for a specimen containing residual stresses that cause a shift in each Bragg peak position with respect to the lattice spacing of the crystal plane $h k l$ in a strain-free sample, $d_{0}$, and the elastic strains $\varepsilon_{h k l}$ are given by: 


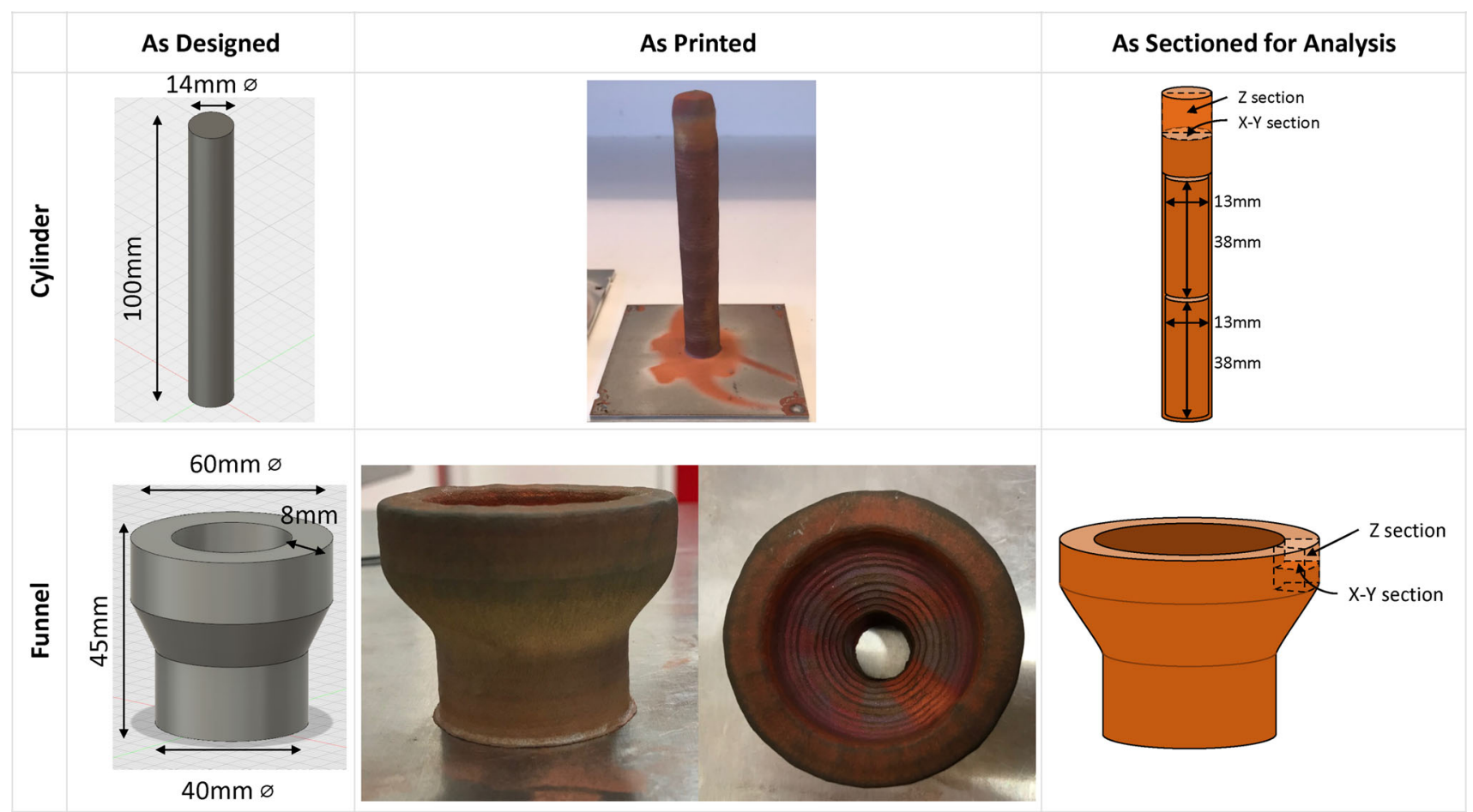

Fig. 1 Design renderings, print, and post-measurement sectioning of cylindrical rod and funnel

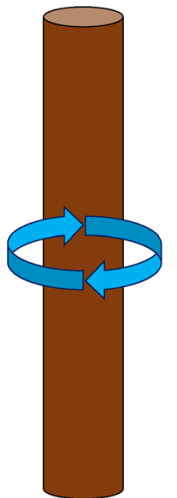

Rotate cylinder during testing
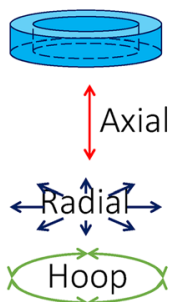

Toroidal voxel

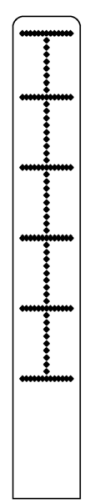

Measurement points

Fig. 2 Voxel shape for the cylinder was generated by rotating the cylinder about its axis during measurement

$\varepsilon_{h k l}=\frac{d_{h k l}-d_{0}}{d_{0}}=\frac{\Delta d_{h k l}}{d_{0}}=\frac{\sin \theta_{0}}{\sin \theta_{h k l}}-1$

where $\theta_{0}$ is the angle at which Bragg peak is observed from the strain-free reference.

In the cylinder specimen, the measurement points (Fig. 2) in the lines running across the specimen combined with the toroidal voxel shape meant that the voxels for all points except in the centre line overlapped. Therefore, the mean peak position and peak fitting error of each pair of overlapping voxels were calculated and the means used to

insert into Eq. 2. Although the funnel was also rotated during testing, the grid of measurement points was only on one side and so no averaging was necessary.

To calculate normal stresses from strains, Hooke's law generalised to the diffraction conditions is used, Eq. 3. Using cylindrical coordinate system for the axial stress component $\sigma_{\mathrm{A}}$, it reads:

$\sigma_{A}=\frac{\left(S_{2}+2 S_{1}\right) \varepsilon_{A}-S_{1}\left(\varepsilon_{H}+\varepsilon_{R}\right)}{S_{2}\left(S_{1}+3 S_{2}\right)}$

where $\varepsilon_{A}, \varepsilon_{H}, \varepsilon_{R}$ are measured strains in the principal directions. Stresses in the other two orthogonal directions are can be obtained by index rotation.

The diffraction elastic constants $S_{1}(h k l)=-v_{h k l} / E_{h k l}$ and $1 / 2 S_{2}(h k l)=\left(1+v_{h k l}\right) / E_{h k l}$ or equivalent pair of $h k l$ dependent Young's modulus $E_{h k l}$ and Poisson ratio $v_{h k l}$ were derived using polycrystalline elasticity models using single-crystal elastic constants of materials using a free online calculator (Ref 33) and the adiabatic elastic constants for copper taken from Ref 34 .

\section{Neutron Strain Scanning: Measurement Procedure and Data Analysis}

The neutron diffraction residual stress measurements were performed on the KOWARI strain scanner at the ANSTO OPAL research reactor (Ref 35). Neutron diffraction is suitable for measuring strain inside bulk components 
because it can deal with greater penetration depths than other strain-scanning techniques, such as synchrotron radiation (Ref 30 ).

During strain scanning, neutrons at a wavelength of $1.55 \AA$ irradiate the specimen and some are elastically diffracted. The $\mathrm{Cu} 311$ reflection produces a Bragg peak at an angle $2 \theta$ of approximately $91^{\circ}$. The scanning was done with $1 \times 1 \times 1 \mathrm{~mm}^{3}$ gauge volume. This was small enough to provide the necessary resolution while producing a sufficiently high count rate for determining strain measurement with the target statistical uncertainty of $5 \times 10^{-5}$ within a reasonable measurement time. The collection time was determined for each measurement point to compensate for differences in attenuation based on specimen geometry, but on average the collection time per measurement position was less than $10 \mathrm{~min}$.

With the given gauge volume, d-spacings in three principal directions were measured: axial; radial; and hoop. The specimens were rotated continuously about the cylinder axis throughout measurement, meaning that the voxel was, in effect, toroidal (Fig. 2). The advantage of this approach is that statistically the results have lower scatter. The grain structure of $\mathrm{Cu}$ can cause substantial scatter in measured d-spacings if samples are static.

To calculate the strain, the following procedure to evaluate $d_{0}$ was used. For the cylindrical sample, the mean of all the $d_{311}$-values measured in the $z=2.5 \mathrm{~mm}$ row (based on $\mathrm{z}=0 \mathrm{~mm}$ at the top of the specimen) was calculated and accepted as d0. This row is the closest to the top (free) end of the specimen, meaning that the stresses in that region are the most relaxed. Additionally, a boundary condition for the radial component to be zero on the cylindrical surface of the sample was used.

For the funnel specimen, strains were calculated using an assumption of zero radial stress, which was the most reasonable assumption due to the presence of two cylindrical surfaces, inner and outer, on which the radial stress is exactly zero, while the thickness was not so great as to develop any significant radial stress component.

Three stress components were calculated from three measured strains using diffraction elastic constants of $\mathrm{Cu}(311)$ reflection. They were $v=0.3536$ and $\mathrm{E}=121.26$, giving $\mathrm{S}_{1}(311)=-2.91 \quad \mathrm{TPa}^{-1}$ and $\quad 1 / 2 \mathrm{~S}_{2}(311)=11.16$ $\mathrm{TPa}^{-1}$. The stress calculation procedure also included error analysis using error propagation for Eq. 2. With the strain target accuracy of $5 \times 10^{-5}$, the evaluated uncertainty of stress was $15 \mathrm{MPa}$ for the cylindrical sample and $\sim 25$ MPa for the funnel. The difference was due to higher neutron absorption in the thicker funnel sample that resulted in longer measurement time, higher relative background in the diffraction pattern, and consequently larger error bars for that sample.
The strain measurement strategies for the two CSAM samples were different due to different geometries and dimensions. Ideally, two full-dimensional maps could be achieved with the strain scanning; however, with the given sample symmetries and limited neutron beamtime, the following approach was adopted:

For the cylinder sample, strain measurements were systematically taken along the central line of the cylinder every $1.5 \mathrm{~mm}$, starting at $2.5 \mathrm{~mm}$ from the top of the specimen and continuing down to $76 \mathrm{~mm}$. In addition, every $15 \mathrm{~mm}$ axial distance, the radial distribution was also measured forming a 2D distributed mesh of measurement points resulting in six horizontal disc layers to be measured (Fig. 2).

A photograph of a polished section of the copper cylinder is shown in Fig. 3. It is possible to discern the difference between the edging material and infill, as well as the layers. The estimated positions of the measurement voxels in the top $(z=2.5 \mathrm{~mm})$ row and uppermost in the central line are indicated. It can be surmised that since the layer thickness of $1.68 \mathrm{~mm}$ is not a rational fraction of the spacing between measurement rows, that the outermost voxels in different rows intersect the edging material to different extents.

\section{Results}

\section{Hardness and Microscopy}

The Vickers hardness of the specimens ranged from $124 \pm 10$ to $134 \pm 10$ (Table 1) and did not show any significant differences between values taken close to the printed surface of the specimen compared with values taken in the centre (Fig. 4), or between the specimens.

An SEM image of the $99 \%$ pure copper powder used for the experiment is shown in Fig. 5. It can be seen that the morphology of the powder is irregular and that there is a broad range of sizes. A light micrograph of polished and etched powder particles embedded in acrylic resin is shown in Fig. 5. It can be seen that there is internal structure to the powder particles, with some internal grains visible.

Light micrographs of a Z-plane section of the cylinder specimen, polished and etched, are also shown in Fig. 5. It can be noted that the powder particles have deformed by flattening in the direction of spray and jetted to give rounded diamond-shaped cross sections. Jetting and the likelihood that some of the junctions between powder particles are not bonded are discussed in Ref 36; however, it is not possible to discern areas of imperfect bonding in Fig. 5. It can be noted that there is internal grain structure 

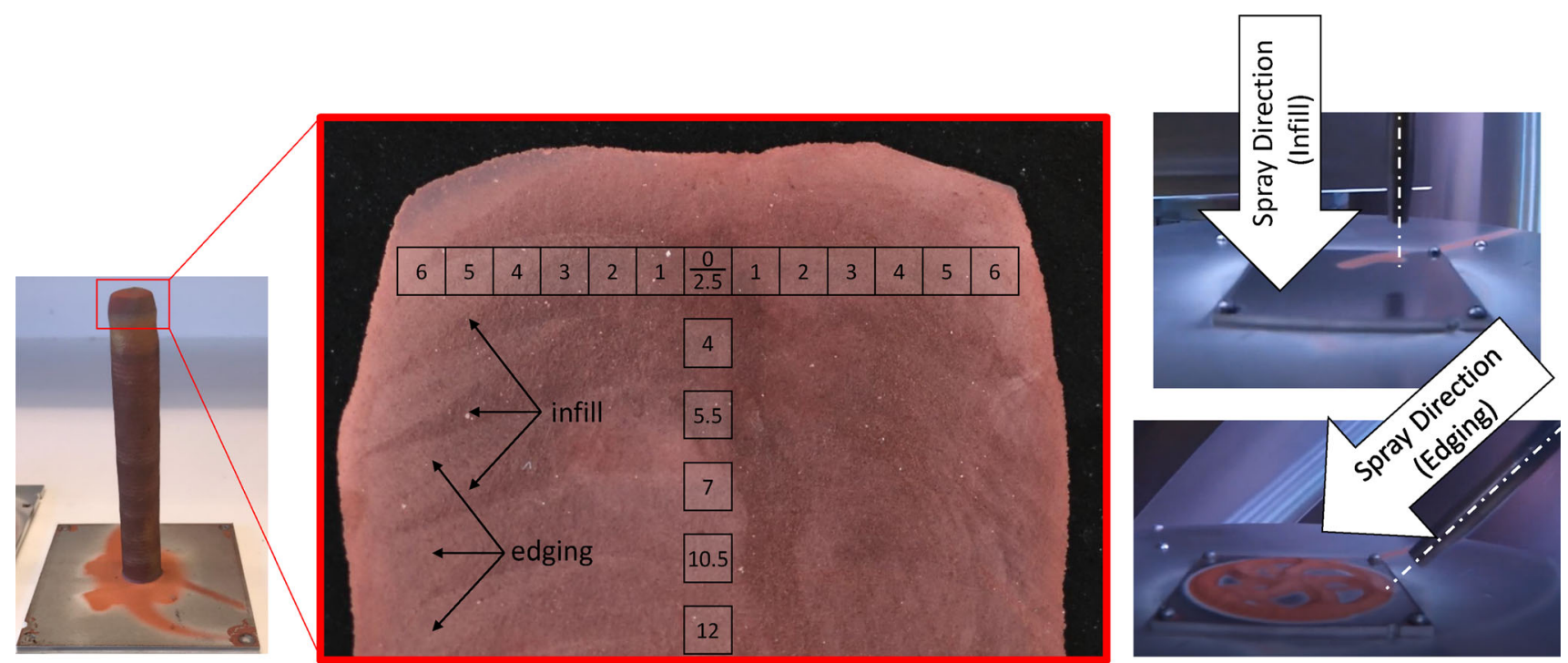

Fig. 3 Photograph showing an exploded view of a polished Z-plane section of the cylinder specimen, with superimposed diagram showing positions of strain measurements in the central cross section of the cylindrical sample. The edging (lighter appearance) and infill (darker appearance) material are distinguished most clearly towards the left of the image but are present on both sides. A visual representation of the spray direction for infill (perpendicular to substrate) and edging $\left(45^{\circ}\right)$ is included
Table 1 Vickers Hardness values from the specimens used in the experiment

\begin{tabular}{lcc}
\hline Specimen & Vickers hardness \pm S.D. & Number of points \\
\hline Cylinder (horizontal plane) & $126 \pm 10$ & 252 \\
Cylinder (vertical plane) & $124 \pm 10$ & 252 \\
Funnel (horizontal plane) & $134 \pm 10$ & 252 \\
Funnel (vertical plane) & $126 \pm 12$ & 252 \\
\hline
\end{tabular}

Fig. 4 Example chart from hardness test results showing all hardness points for the vertical plane section of the cylinder sample plotted against $\mathrm{Y}$ distance (the grid position, where positive numbers approach the specimen printed edge). The trendline shows no differences between the hardness of points close to the edge versus the centre

\section{Hardness vs Y Distance, Cylinder, Vertical Plane}

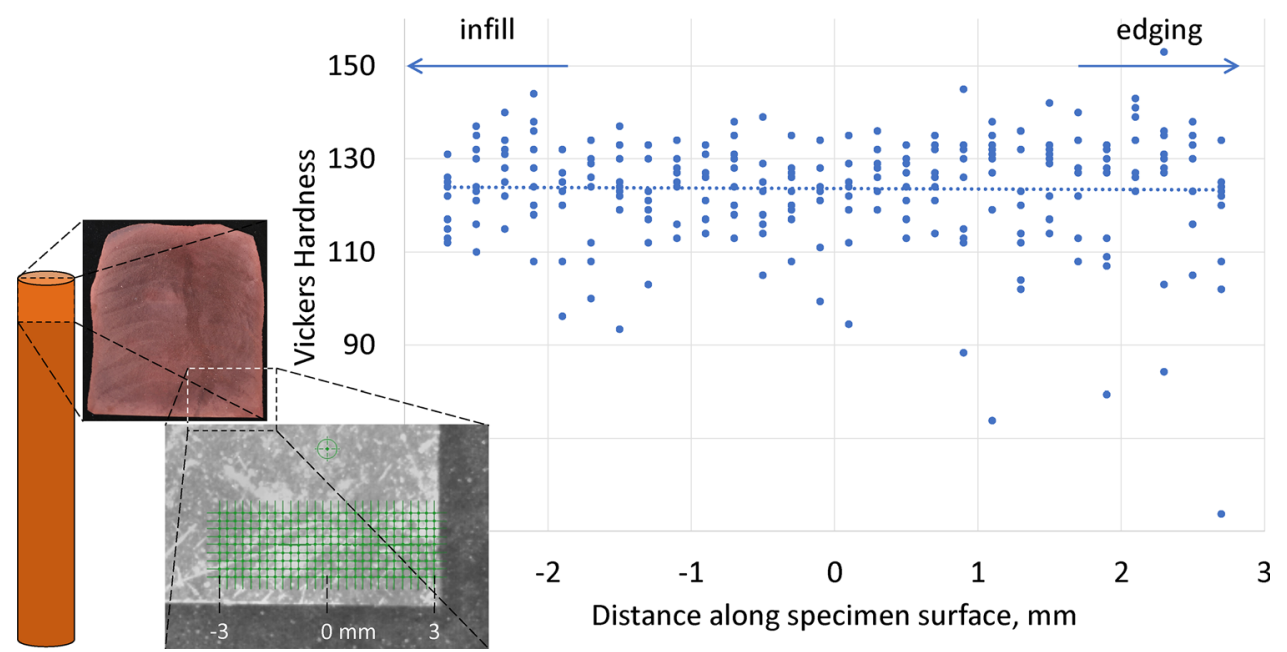

to what was formerly the separate particles. It is surmised that the grain structure visible in the embedded powder has given rise to the grain structure in the printed material despite the jetting.

\section{Compressive Testing}

Compressive testing of five compression test pieces yielded Young's modulus (elastic stiffness in compression, longitudinal direction) of $115.9 \mathrm{GPa} \quad$ (s.d. $=20.1, \mathrm{n}=16$ including repeat tests of the same cylinders) and a 


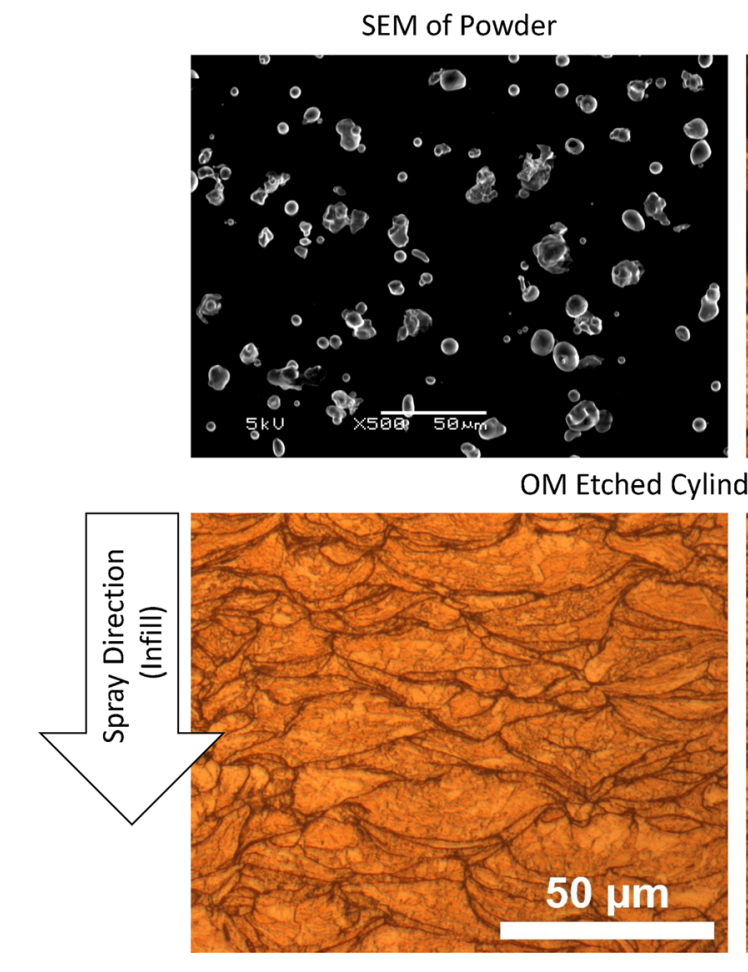

Fig. 5 Images of the powder and printed specimen. Scanning electron micrograph showing the morphology of the copper powder used for the experiment. Light micrograph indicating internal grain structure of the copper powder used for the experiment. The powder has been embedded, polished and etched. Light micrographs of polished and etched section of the cylinder showing the deformed

Poisson's ratio of 0.355 (s.d. $=0.05, \mathrm{n}=16$ ). These results being close to the values calculated from polycrystalline elasticity models using single-crystal elastic constants, and the differences well within a standard deviation, it was decided not to recalculate the stress results based on the compressive testing results.

\section{Residual Stresses}

The measurements of the two strain components along the central line of the cylindrical sample are shown in Fig. 6. For this central line, the hoop and radial components are the same due to the geometry of a cylinder. Noting that the cylinder was $100 \mathrm{~mm}$ in height, the axial strain can be seen to rise until approximately $10-15 \mathrm{~mm}$, then reaching a plateau with deviations above and below an approximately constant line. A statistical check of the data in the region defined to be a plateau showed that this is a constant value with oscillations within error bars. Thus, beyond $15 \mathrm{~mm}$ axial distance, the stress can be considered steady state.

The overall 2D maps of all three components, including radial lines, in the cylinder are shown in Fig. 7. Similar oscillations of stress are visible, but it is postulated that the
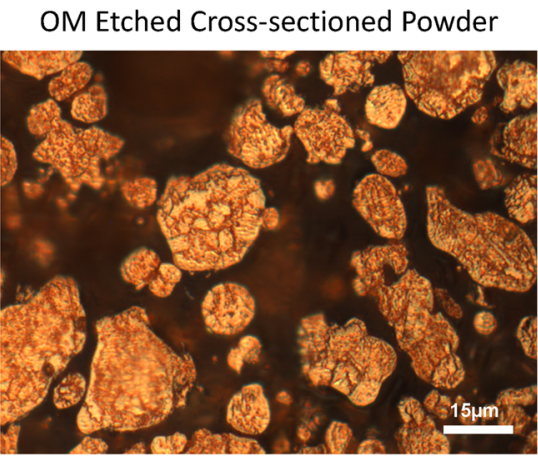

der Cross-section

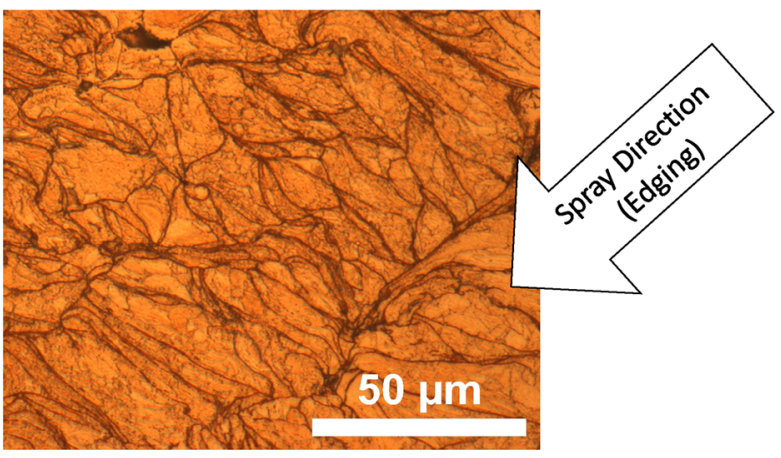

powder particles within the structure of the 3D-printed copper. The particle boundaries show as dark lines, and within each particle, some grain structure is visible. The two areas shown are taken from the centre and near the edge of the specimen, and spray directionality is visible in the structure

steady-state stress state in the middle of the cylinder averaging over all radial lines can result in radial stress profiles with higher statistical quality.

In Fig. 8, each of the mean stress profiles is plausibly similar to parabolic profiles such as those used in models of residual stresses in quenched cylindrical specimens in Ref 37 and 38. The axial stresses have the greatest magnitude, and positive (tensile) stresses are present in the centre and negative (compressive) stresses near the edges. The hoop stress has an intermediate magnitude with positive (tensile) stresses in the centre and negative (compressive) stresses near the edges. The radial stress has the lowest magnitude but stays tensile across the specimen width (noting that the errors are greater than the stresses at several points across the specimen width).

The general form of the stress profiles in Fig. 8 appears to be similar to those shown for a cylinder in Ref 37 . The radial stresses theoretically reduce to zero at the surface of the cylindrical specimen, and although practical measurements are done some distance away from the surface, the data can reasonably be interpolated. This validates the assumed $\mathrm{d}_{0}$ value. 
Fig. 6 Measured axial and hoop (or radial) strains from the central line of the cylindrical specimen

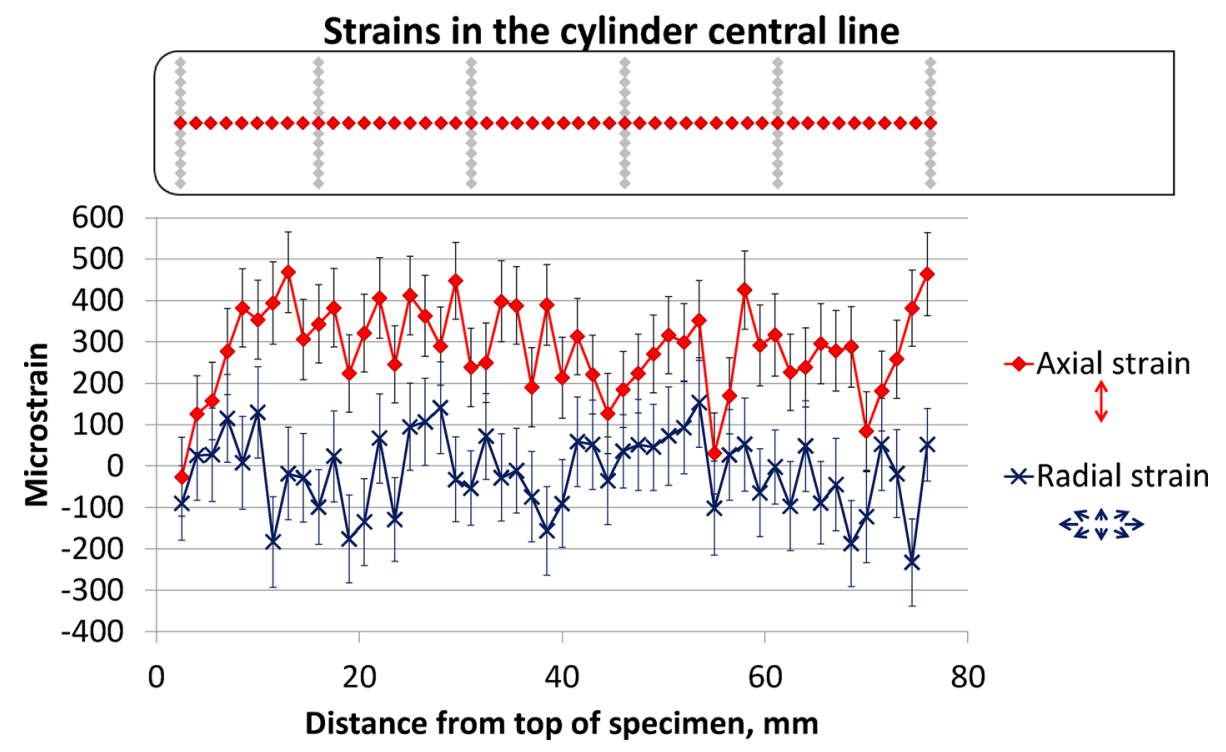

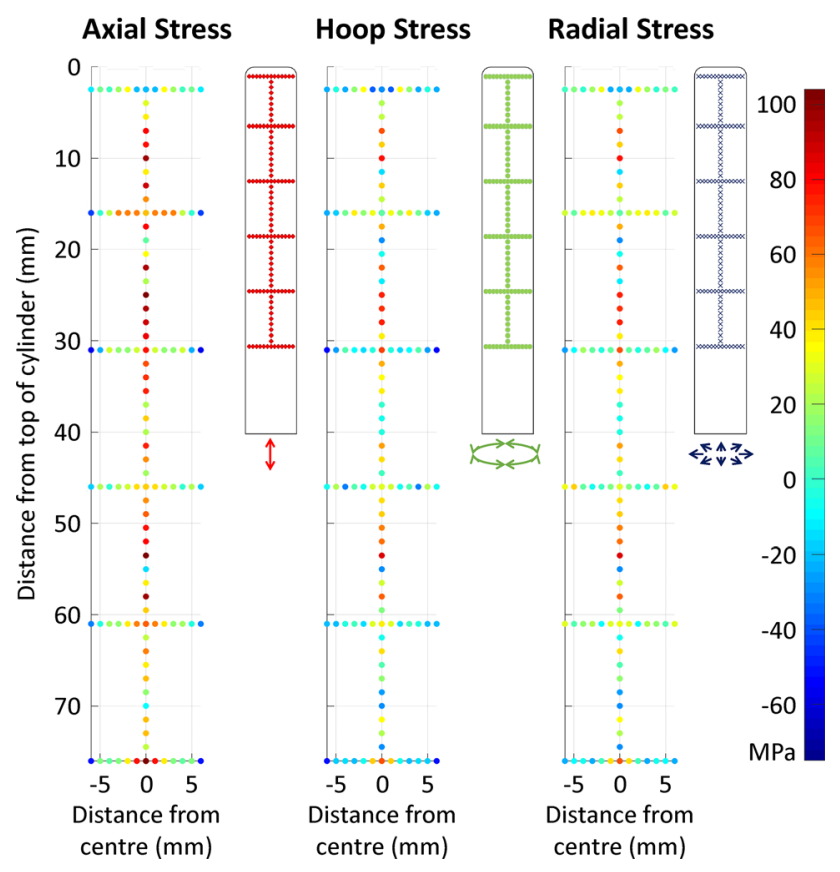

Fig. 7 Calculated residual stresses in the cylindrical specimen

For the funnel specimen, the axial and hoop stress components calculated using an assumption of zero radial stress are shown in Fig. 9. Similar to the cylinder specimen, there are significant variations ( $\sim 25 \mathrm{MPa}$ error bars) of statistical nature from point to point, but the stresses (both axial and hoop) near the outer surface of the funnel are clearly compressive, compensated by the tensile stresses in the centre.

It is observed that in the middle of the sample the axial stress is generally more tensile than the hoop stress. This is similar to the relationship between axial and hoop stresses in the centre of the cylindrical sample.

Table 2 summarises the residual stress maximums and minimums for the two specimens. The stresses in Table 2 were calculated using Eq. 3 and the equivalents in the other isometric directions. The stress error values in Table 2 were calculated by error propagation technique using the standard deviations from the lattice spacing peak fitting (Eq. 2 and Eq. 3). The maximum and minimum stresses in Table 2 are accompanied by the error values calculated for the measurement point in question. The stress ranges in Table 2 are accompanied by errors that are the sum of the error values for the minimum and maximum individual points used to calculate the range.

\section{Discussion}

The main result of the stress analysis of the cylindrical sample (in the central, steady-state region) is that on the surface the residual stress is compressive, more or less biaxial with magnitude of approximately $-40 \mathrm{MPa}$.

The surface stress is indicative of the deposition stress; thus, for the cylindrical sample the deposition stress is around -40 to $-50 \pm 10 \mathrm{MPa}$ (depending interpolation of stress to the surface of the sample). This compressive stress magnitude is similar to that obtained for a copper flat coating cold-sprayed on copper substrate sample, $-41 \pm 12 \mathrm{MPa}$, and not far away from the value $-85 \pm 20 \mathrm{MPa}$ reported for a $\mathrm{Cu} / \mathrm{Al}$ coating sample (Ref 29).

It is likely that peening is the dominant effect on residual stress driver in the bulk cold-spray components for this experiment because the overall stress near the surface 
Fig. 8 Stresses calculated by taking the mean of all the steady-state strains. Error bars show maximum errors at each point

\section{(a)}
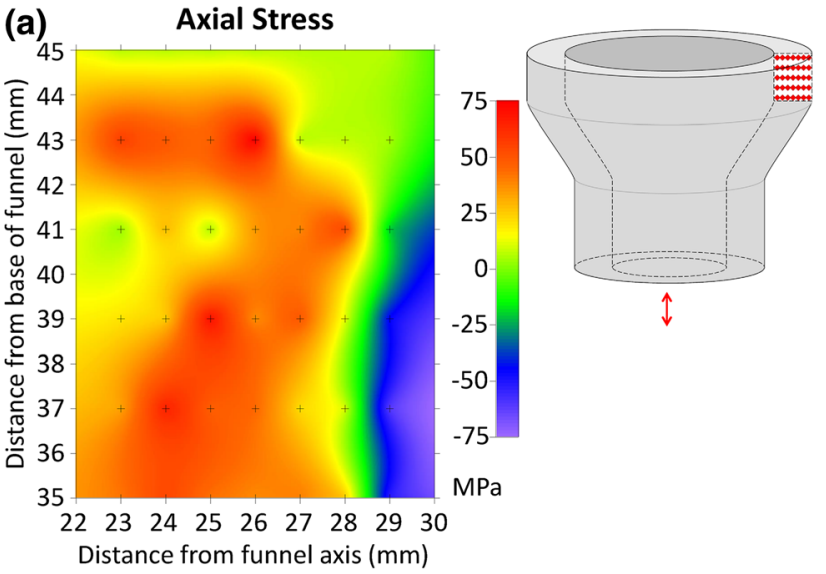

(b) Hoop Stress

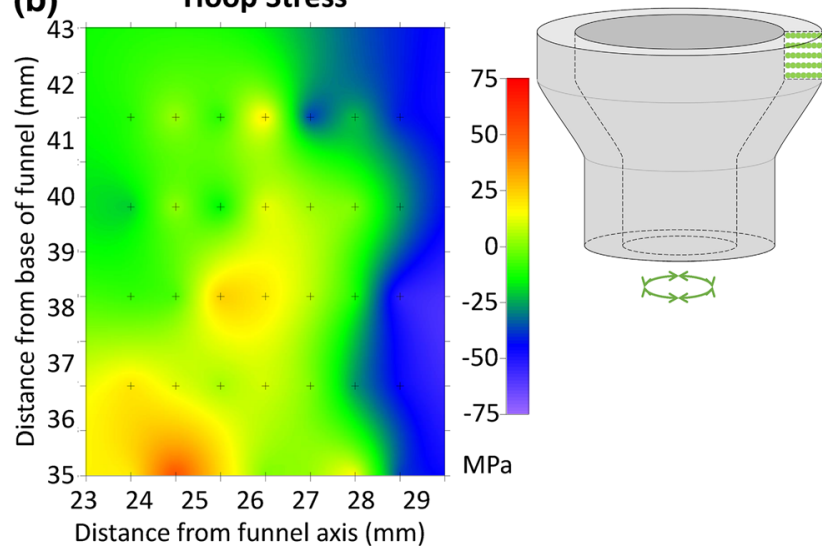

Fig. 9 Calculated residual stresses in the funnel-like specimen: (a) axial and (b) hoop. Note that the graph extrapolates the data at the top and sides and between points (shown by small crosses)
Mean stresses at steady state

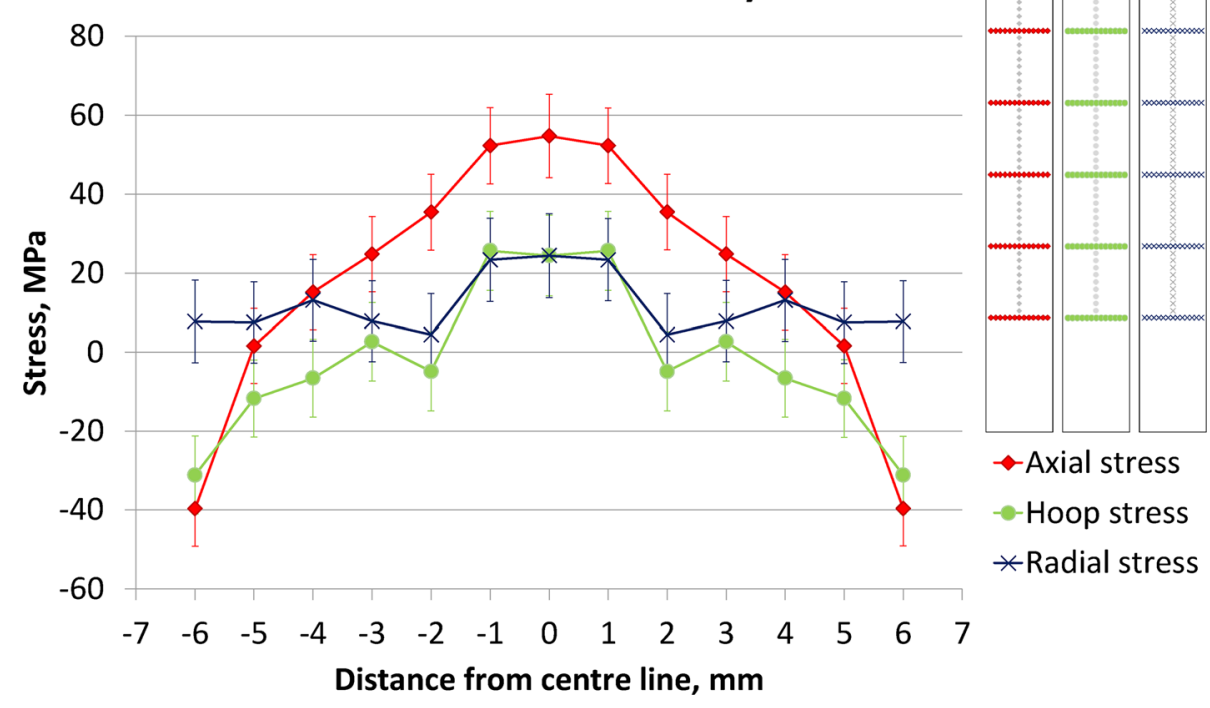

was compressive. Prior results (Ref 15-25, 29) for coatings show peening effects to contribute compressive deposition stress, and thermal mismatch and quenching to contribute tensile deposition stress. It is logical that thermal mismatch effects likely do not extend far to the bulk specimens in this experiment because there is a much greater distance between the part of the material being measured and the substrate compared with coatings. Quenching effects, though they could contribute to bulk cold-spray specimens, are likely suppressed in this particular CSAM system due to the carrier gas temperatures. The SPEE3D machine used for this experiment had a carrier gas temperature of $400{ }^{\circ} \mathrm{C}$, and this is low compared with the systems in the literature that reported quenching dominant deposition stress $\left(800{ }^{\circ} \mathrm{C}\right.$ for 316 stainless steel, Ref $18 ; 1100{ }^{\circ} \mathrm{C}$ for titanium, Ref 25).

Overall, it can be concluded that in all reported cases and in the given study the compressive deposition stress in the range of -20 to $-70 \mathrm{MPa}$ is more or less typical for cold-spray technical realisation in copper at similar carrier gas temperatures. This is most likely related to the narrow optimal spraying parameter window, while variations in the stress magnitude may be related to variations in the spray parameters within this window such as particle velocity, particle (gas) temperature, particle size, stand-off distance, and spray angle.

Although the funnel sample has different geometries, some estimate of the deposition stress can be made in this case as well. If we consider stress on the outer surface, then from Fig. 8 it can be concluded that stress is also compressive on the surface, approximately biaxial and with magnitude of approximately $-50 \pm 15 \mathrm{MPa}$. This value is 
Table 2 Minimum and maximum residual stresses (MPa) and ranges for the CSAM printed components

\begin{tabular}{|c|c|c|c|c|}
\hline & \multicolumn{2}{|c|}{ Cylinder } & \multicolumn{2}{|c|}{ Funnel } \\
\hline & Maximum compressive & Maximum tensile & Maximum compressive & Maximum tensile \\
\hline Axial stress, $\mathrm{MPa}$ & $-58 \pm 16$ & $103 \pm 16$ & $-59 \pm 23$ & $60.2 \pm 22.7$ \\
\hline Hoop stress, $\mathrm{MPa}$ & $-55 \pm 17$ & $85 \pm 28$ & $-53.6 \pm 24$ & $50.7 \pm 24.6$ \\
\hline Radial stress, $\mathrm{MPa}$ & $-30 \pm 22$ & $85 \pm 28$ & - & - \\
\hline
\end{tabular}

Fig. 10 Stresses calculated by taking the mean of all the steady-state strains (excluding the top line)

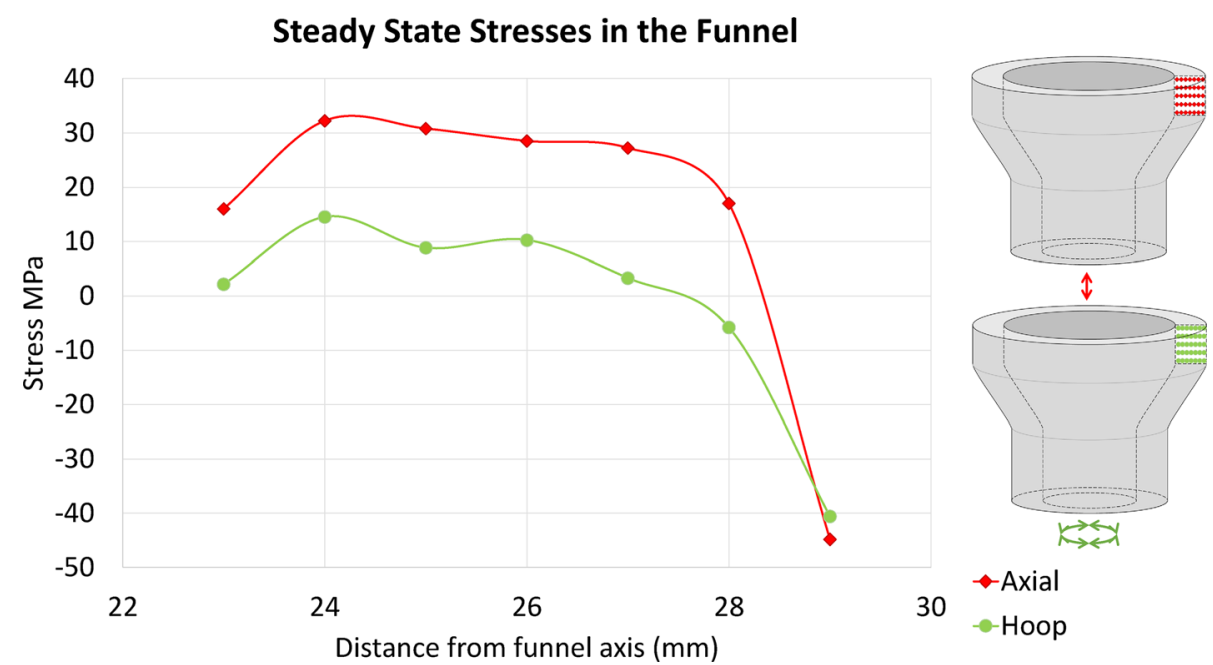

close to the value of the deposition stress in the cylindrical sample $(-40$ to $-50 \pm 10 \mathrm{MPa})$.

The stress state for the funnel, however, is not symmetric for the outer and inner surfaces, as can be seen in Fig. 9. This is not surprising because the two surfaces are not equivalent: there is a geometric factor in the stress balance (the balance works as $r \sigma_{A}$, not just $\sigma_{A}$ ); also there must be some different thermal conditions for the two surfaces as well as particle stream angular characteristics (for example, the inner surface cannot be sprayed at $90^{\circ}$ angles or perpendicular to surface because of funnel geometry limitations since in this case nozzle or particle stream would intersect the opposite wall). Spraying under lower angle apparently reduced the peening effect leading to a lower inner surface stress value than on the outer surface. However, a clear tendency for stresses to become more compressive on the inner surface in comparison with the centre is evident from Fig. 10.

The residual stresses were lower than those reported for cast copper (approximately 50 to $200 \mathrm{MPa}$, Ref 13) and alternative methods of additively manufactured metals (approximately -250 to $+250 \mathrm{MPa}$, Ref 11 ). However, the measured stresses had similar or greater magnitudes than those reported for cold-sprayed coatings (approximately -80 to $+20 \mathrm{MPa}$, Ref 24 , and approximately -9 to +3 MPa, Ref 23). Relatively low residual stresses can be advantageous if the splat boundaries can be healed (Ref 39) via heat treatment to give good material properties. Future work is warranted to investigate cold-sprayed residual stress measurements after heat treatment, as well as heat treatment optimisation for mechanical properties.

Evidence points to cold-spray material having an upper limit of residual stress after deposition. Three possible reasons for an upper limit of residual stress are discussed in the paragraphs following.

One limiting factor could be plastic flow at stresses above yield strength. Reference 29 discusses a relationship between yield stress and deposition stress in FCC materials. Whether such a relationship is valid for copper or not, it should also be considered that, if otherwise unconstrained, a ductile material should experience stress relief via plastic flow at stresses above yield. Reported yield strengths for copper are highly variable. Yield stress values for various materials in the range $99 \%$ to $99.99 \%$ copper have been reported between 15 and $750 \mathrm{MPa}$, depending strongly on annealing and cold working, composition, and 
grain size (Ref 40, 41).The yield stress for the sprayed $99 \%$ pure copper material in this experiment has not been measured, due to failure before yield in tension and compressive testing limited to the elastic region only. Although the information available remains limited, yield stress as a limit to deposition stress remains plausible.

An additional factor limiting deposition stress could be in situ annealing during deposition. Heat of friction arising from the impact and deformation of particles as well as the temperature of the carrier gas could contribute to the particles experiencing some degree of annealing (Ref 42, 43). Reference (Ref 43) models the temperature of a $25-\mu \mathrm{m}$ copper particle impacting at $550 \mathrm{~ms}^{-1}$, finding $62.7 \mathrm{~ns}$ after impact that temperature in the particle rises to approximately $1350 \mathrm{~K}$, and at the same time, stress in the particle drops from upwards of $500 \mathrm{MPa}$ to around zero. The temperature rise is attributed to impact and shearing. Modelling the temperature-time profile for the parameters of the present experiment is far beyond its scope; however, the idea of in situ annealing during deposition of CSAM copper should not be ruled out.

Further, measurable deposition stresses could be limited by micro-scale processes, for example micro-cracking due to inability to transfer stress across splat boundaries. Some discussion on these phenomena in cold-sprayed aluminium 6061 coatings is given in Refs (Ref 44), (Ref 45), and (Ref 46). Weakly bonded interfaces at certain regions of the splat boundaries are expected in cold-spray material. Such defects at the splat interface have been shown to be reduced by heat treatment (Ref 39, analysis via EBSD grain boundary angle and tensile strength testing). Since the specimens in the present experiment are not heat treated, the weak interfaces cannot carry high loads and additional stress could cause cracking, tending to limit the stress retained in the material.

It should be noted that the stresses and strains that have been measured are macro in scale or macro-stress. The spatial resolution of $1 \mathrm{~mm}^{3}$ is much greater than the grain and splat structures noted in Fig. 5, and even if the voxel size is reduced to smaller than about $0.5 \mathrm{~mm}^{3}$, it would be an order of magnitude larger than the particles. Numerical modelling (Ref 10) of cold-spray processes suggests that there could be greater oscillations of tensile and compressive stresses in small regions of the scale of a splat, so called micro-stresses, as well as localised severe plastic strains. In our study, the effect of micro-stress is likely reflected in the neutron diffraction peak broadening effect. It was noted that the width of the fitted $\mathrm{Cu}$ (311) peaks varied between the specimens described in the present study and an additional CSAM copper specimen, not otherwise described here but heat-treated at $400{ }^{\circ} \mathrm{C}$ for $20 \mathrm{~min}$. Broader peaks in the as-printed samples gave a very general indication that micro-stresses are present.
However, without further information on dislocation density, grain size in the heat treated sample, and other factors, any quantitative treatment of micro-stress based on peak broadening has some degree of uncertainty. However, the order of magnitude of micro-stress can be estimated based on simplifications and large assumptions. Thus, assuming hydrostatic nature of micro-stress and no contribution from the dislocation density and grain size to the peak width, the estimated magnitude of micro-stress is approximately 400-500 MPa. If correct, this is much greater than the measurable macro-stresses (Table 2). However, since micro-stress is balanced to zero in any macroscopic volume, this does not lead to any overall distortions, while even small macro-stress over large distances can have this effect. To learn more about localised micro-stresses, further analysis of neutron experimental data in terms of peak broadening analysis is required, and synchrotron strain measurements with much higher spatial resolution within the surface regions can be attempted.

In contrast to modelling of micro-stresses which appears to show large oscillations, (Ref 27, 28), the macro-stress and strain variations across and along the specimens are smooth within statistical uncertainties. These errors are mostly due to limited neutron counting statistics (or peak fitting errors), though there might be some additional contribution from the localised (micro-scale) strains in the specimen since number of measured grains in their individual stress state is finite. However with the continuous rotation techniques applied, the bulk volume averaging provides the best possible statistical result.

Further, the jetting of particles causes severely plastically deformed regions, likely accompanied by high stresses. However, plastic deformation is not "visible" to the neutron technique, since it is based on crystalline spacing, and therefore detects elastic strains only.

Given the sample geometry and the spatial resolution was set to $1 \mathrm{~mm}^{3}$, a measurement at or very close to the surface was not possible. Given this spatial resolution limitation, it is possible that some greater residual strains than were observed were present in the edging regions of the specimens. Future experimental aims could be to (1) refine spatial resolution of stress measurements to obtain values nearer the surface (e.g. flat coatings can be done with higher resolution as fine as $0.2 \mathrm{~mm}$ ) and (2) measure strains in the edging regions. It may be desired to use a long cuboid voxel. This would achieve good spatial resolution without overly increasing count time. Further, synchrotron $\mathrm{x}$-ray strain scanning may give information about the exterior surfaces.

From the AM point of view, CSAM has certain advantages regarding the residual stress if peening-dominant printing parameters and material combinations are used (Ref 15-17, 21-24). Firstly, moderately compressive 
stresses on the surface are, in fact, beneficial because they prevent micro-crack formation, opening, and propagation on the surface. Secondly, the moderate magnitude of the residual stresses does not cause large distortions; therefore, CSAM component shapes can be well-predicted compared with the design. Thirdly, the compressive stress can be controlled by changing spraying parameters, specifically particle/gas temperature; it can be adjusted to produce almost zero stress, and in some cases, it can be pushed into regime of tensile stress on the surface, as in Refs (Ref 18) and (Ref 25), although tensile stress on the surface is not desirable.

\section{Conclusions}

The goal of the research was to quantify the deposition stress in bulk copper components produced using a new CSAM deposition method where previously cold-spray deposition stress has been reported only for coatings. The angle $2 \theta$ of the 311 neutron diffraction peak at multiple $1 \mathrm{~mm}$ cubic locations in two bulk CSAM parts was measured, and stresses in three orthogonal directions calculated. Overall, the results show:

- Neutron diffraction can provide stress distribution in complex 3D samples made by CSAM with sufficient accuracy of 15-25 MPa.

- Residual stresses from the copper CSAM cylinder and funnel (Table 2) were compared with the available residual stresses reported for cold-sprayed copper coatings (Ref 14-17) and found to be broadly in line with compressive deposition stress (or surface stress) of approximately $-50 \mathrm{MPa}$.

- The measured residual stress profiles did not show the large magnitudes associated with either cast materials or powder-bed-based methods of 3D metal printing that use melting nor tensile surface stress that is more common in SLM.

- Since compressive stresses of moderate magnitude on surface are beneficial in their ability to prevent surface cracking, CSAM can be viewed as an AM technique that, with appropriate process parameters, is advantageous in terms of residual stress formation in addition to other advantages such as high deposition rate and low deposition temperature.

To further investigate deposition stress, future work is warranted to investigate cold-sprayed residual stress measurements after heat treatment, as well as heat treatment optimisation for mechanical properties.

Acknowledgements Funding from the Cooperative Research Centres Projects and the use of the ANSTO neutron facility for awarded beamtime on KOWARI neutron diffractometer under proposal ID 7104 are kindly acknowledged.

Open Access This article is licensed under a Creative Commons Attribution 4.0 International License, which permits use, sharing, adaptation, distribution and reproduction in any medium or format, as long as you give appropriate credit to the original author(s) and the source, provide a link to the Creative Commons licence, and indicate if changes were made. The images or other third party material in this article are included in the article's Creative Commons licence, unless indicated otherwise in a credit line to the material. If material is not included in the article's Creative Commons licence and your intended use is not permitted by statutory regulation or exceeds the permitted use, you will need to obtain permission directly from the copyright holder. To view a copy of this licence, visit http://creativecommons. org/licenses/by/4.0/.

\section{References}

1. S. Hashimi, G. Ferreira Batalha, C.J. Van Tyne, and B. Yilbas, Comprehensive Materials Processing, Elsevier, Amsterdam, 2014

2. J. Pattison, S. Celotto, R. Morgan, M. Bray, and W. O'Neill, Cold Gas Dynamic Manufacturing: A Non-thermal Approach to Freeform Fabrication, Int. J. Mach. Tool Manuf., 2006, 47(3-4), p 627-634

3. S. Yin, P. Cavaliere, B. Aldwell, R. Jenkins, H. Liao, W. Li, and R. Lupoi, Cold Spray Additive Manufacturing and Repair: Fundamentals and Applications, Addit. Manuf., 2018, 21, p 628-650

4. Metal 3D Printing at Production Speeds, Assembly, 2017, p 88

5. Jasmina, The World's First Commercial LightSPEE3D Printer Boosts Medal Additive Manufacturing, Australian Manufacturing, 2017. https://www.australianmanufacturing.com.au/47541/ the-worlds-first-commercial-lightspee3d-printer-boosts-medaladditive-manufacturing Accessed 18 February 2020

6. Machines. https://www.titomic.com/machines.html. Accessed 18 February 2020

7. M. Jahedi, S. Gulizia, B. Tiganis, C. Tang, and S. Zahiri, Manufacture of Pipes, WO2009109016 (2009)

8. S. Zahiri, M. Jahedi, K. Hooper, W. Bardsley, S. Gulizia, and C. Tang, Method of Forming Seamless Pipe of Titanium and/or Titanium Alloys, WO2014085846 (2013)

9. D. Ikeuchi, A. Vargas-Uscategui, X. Wu, and P. King, Neural Network Modelling of Track Profile in Cold Spray Additive Manufacturing, Materials, 2019, 12(17), p 2827-2838

10. R.N. Raoelison, C. Verdy, and H. Liao, Cold Gas Dynamic Spray Additive Manufacturing Today: Deposit Possibilities, Technological Solutions and Viable Applications, Mater. Des., 2017, 133, p 266-287

11. R. Cottam, J. Wang, and V. Luzin, Characterization of Microstructure and Residual Stress in a 3D H13 Tool Steel Component Produced by Additive Manufacturing, J. Mater. Res., 2014, 29(17), p 1978-1986

12. V. Luzin and N. Hoye, Stress in Thin Wall Structures Made by Layer Additive Manufacturing, Mater. Res. Proc., 2017, 2, p 497502

13. H. Gripenberg, Residual Stress Investigation of Copper Plate and Canister EB-Welds-Complementary Results, Posiva Working Report 2009-21, 2009, (Eurajoki, Finland), Posiva OY

14. R.C. McCune, W.T. Donlon, O.O. Popoola, and E.L. Cartwright, Characterization of Copper Layers Produced by Cold Gas-Dynamic Spraying, J. Therm. Spray Technol., 2000, 9(1), p 73-82 
15. V. Luzin, K. Spencer, and M.-X. Zhang, Residual Stress and Thermo-Mechanical Properties of Cold Spray Metal Coatings, Acta Mater., 2011, 59(3), p 1259-1270

16. T. Suhonen, T. Varis, S. Dosta, M. Torrell, and J.M. Guilemany, Residual Stress Development in Cold Sprayed $\mathrm{Al}, \mathrm{Cu}$ and $\mathrm{Ti}$ Coatings, Acta Mater., 2013, 610(17), p 6329-6337

17. K. Spencer, V. Luzin, and M. Zhang, Structure and Properties of Cold Spray Coatings, Mater. Sci. Forum, 2010, 654-656, p 18801883

18. V. Luzin and D. Fraser, Neutron Through-Thickness Stress Measurements in Two-Phase Coatings with High Spatial Resolution, Mater. Res. Proc., 2018, 4, p 111-116

19. W.B. Choi, L. Li, V. Luzin, R. Neiser, T. Gnaeupel-Herold, H.J. Prask, S. Sampath, and A. Gouldstone, Integrated Characterization of Cold Sprayed Aluminum Coatings, Acta Mater., 2007, 55(3), p 857-866

20. S. Rech, A. Trentin, S. Vezzu, E. Vedelago, J.-G. Legoux, and E. Irissou, Different Cold Spray Deposition Strategies: Single- and Multi-layers to Repair Aluminium Alloy Components, J. Therm. Spray Technol., 2014, 23(8), p 1237-1250

21. K. Spencer, V. Luzin, N. Matthews, and M.-X. Zhang, Residual Stresses in Cold Spray Al Coatings: The Effect of Alloying and of Process Parameters, Surf. Coat. Technol., 2012, 206(s19-20), p 4249-4255

22. J. Matějíček, S. Sampath, T. Gnäupel-Herold, and H.J. Prask, Residual Stress in Sprayed Ni $+5 \%$ Al Coatings Determined by Neutron Diffraction, Appl. Phys. A Mater. Sci. Process., 2002, 74(suppl. 1), p S1692-S1694

23. M. Saleh, V. Luzin, and K. Spencer, Analysis of the Residual Stress and Bonding Mechanism in the Cold Spray Technique Using Experimental and Numerical Methods, Surf. Coat. Technol., 2014, 252, p 15-28

24. D. Boruah, X. Zhang, and M. Doré, Theoretical Prediction of Residual Stresses Induced by Cold Spray with Experimental Validation, Multidiscip. Model. Mater. Struct., 2015, 15(3), p 599-616

25. D. Boruah, B. Ahmad, T.L. Lee, S. Kabra, A.K. Syed, P. McNutt, M. Doré, and X. Zhang, Evaluation of residual stresses induced by cold spraying of Ti-6Al-4V on Ti-6Al-4V substrates, Surf. Coat. Technol., 2019, 374, p 591-602

26. Y.C. Tsui and T.W. Clyne, An Analytical Model for Predicting Residual Stress in Progressively DepositedCoatings Part 1: Planar Geometry, Thin Solid Films, 1997, 306(1), p 23-33

27. G. Benenati and R. Lupoi, Development of a Deposition Strategy in Cold Spray for Additive Manufacturing to Minimize Residual Stress, Proc. CIRP, 2016, 55, p 101-108

28. W. Li, K. Yang, D. Zhang, and X. Zhou, Residual Stress Analysis of Cold-Sprayed Copper Coatings by Numerical Simulation, $J$. Therm. Spray Technol., 2016, 25(1-2), p 131-142

29. V. Luzin, K. Spencer, M. Zhang, N. Matthews, J. Davis, and M. Saleh, Residual Stresses in Cold Spray Coatings, Cold-Spray Coatings: Recent Trends and Future perspectives, P. Cavaliere, Ed., Springer, Cham, 2018, p 451-480

30. R. Sinclair, M. Preuss, and P.J. Withers, Imaging and Strain Mapping Fibre by Fibre in the Vicinity of a Fatigue Crack in a Ti/ SiC fibre composite, Mater. Sci. Technol., 2005, 21(1), p 27-34
31. M.T. Hutchings, P.J. Withers, T.M. Holden, and T. Lorentzen, Introduction to the Characterization of Residual Stress by Neutron Diffraction, Taylor \& Francis Ltd, London, 2005

32. M.E. Fitzpatrick and A. Lodini, Ed., Analysis of Residual Stress by Diffraction using Neutron and Synchrotron Radiation, Taylor \& Francis, London, 2003

33. K. Suzuki, X-ray and Mechanical Elastic Constants for Cubic System by Kröner model, https://www.rigaku.co.jp/app/kroner/ kroner_c.html. Accessed 2 July 2019

34. C.V. Raman and D. Krishnamurti, Evaluation of the Four Elastic Constants of Some Cubic Crystals, Memoir No. 76 from the Raman Research Institute, Bangalore 6, Proc. Indian Acad. Sci., 1955, A42, p 111-130

35. O. Kirstein, V. Luzin, and U. Garbe, The Strain-Scanning Diffractometer Kowari, Neutron News, 2009, 20(4), p 34-36

36. M. Hassani-Gangaraj, D. Veysset, K.A. Nelson, and C.A. Schuh, Impact-Bonding with Aluminum, Silver, and Gold Microparticles: Toward Understanding the Role of Native Oxide Layer, Appl. Surf. Sci., 2019, 476, p 528-532

37. V. Luzin, Use of the Eigenstrain Concept for Residual Stress Analysis, Mater. Sci. Forum, 2014, 768-769, p 193-200

38. R. Fernández, S. Ferreira-Barragáns, J. Ibáñez, and G. GonzálezDoncel, A Multi-Scale Analysis of the Residual Stresses Developed in a Single-Phase Alloy Cylinder After Quenching, Mater. Des., 2018, 137(5), p 117-127

39. A.C. Hall, D.J. Cook, R.A. Neiser, T.J. Roemer, and D.A. Hirschfield, The Effect of a Simple Annealing Heat Treatment on the Mechanical Properties of Cold-Sprayed Aluminum, J. Therm. Spray Technol., 2006, 15(2), p 233-238

40. C.J. Smithells, Ed., Metals Reference Book, 5th ed., Butterworths, London, 1976, p 1104-1106

41. Y. Wang, J. Shang, Q. Wei, and Y. Zhao, Grain Size Effects on The Compressibility and Yield Strength of Copper, J. Phys. Chem. Solids, 2013, 74(1), p 75-79

42. P.C. King, G. Bae, S.H. Zahiri, M. Jahedi, and C. Lee, An Experimental and Finite Element Study of Cold Spray Copper Impact onto Two Aluminum Substrates, J. Therm. Spray Technol., 2010, 19(3), p 620-634

43. G. Bae, Y. Xiong, S. Kumar, K. Kang, and C. Lee, General Aspects of Interface Bonding in Kinetic Sprayed Coatings, Acta Mater., 2008, 56(17), p 4858-4868

44. P. Nautiyal, C. Zhang, V. Champagne, B. Boesl, and A. Agarwal, In-Situ Creep Deformation of Cold-Sprayed Aluminum Splats at Elevated Temperatures, Surf. Coat. Technol., 2019, 372, p 353360

45. P. Nautiyal, C. Zhang, V.K. Champagne, B. Boesl, and A. Agarwal, In-Situ Mechanical Investigation of the Deformation of Splat Interfaces in Cold-Sprayed Aluminum Alloy, Mater. Sci. Eng. A, 2018, 737, p 297-309

46. A. Loganathan, S. Rengifo, A.F. Hernandez, Y. Emirov, C. Zhang, B. Boesl, J. Karthikeyan, and A. Agarwal, Effect of 2D WS2 Addition on Cold-Sprayed Aluminum Coating, J. Therm. Spray Technol., 2017, 26(8), p 1585-1597

Publisher's Note Springer Nature remains neutral with regard to jurisdictional claims in published maps and institutional affiliations. 